\title{
Políticas de comunicação no Brasil: a proposta de um novo marco regulatório para a radiodifusão
}

\section{Políticas de la Comunicación en Brasil: la proposición de un nuevo marco regulatorio para la radiodifusión}

\section{Communication Policies in Brazil: the proposal of a new regulation for media broadcasting}

\author{
Carlos Henrique Demarchi' \\ Maria Teresa Miceli Kerbauy"
}

Palavras chave:

O presente artigo analisa a proposta de um novo marco regulatório para a comunicação no Brasil. Descreve, sob o ponto de vista dos aportes

Marco regulatório

Políticas de comunicação teóricos da economia política da comunicação, como a legislação existente e a ausência de intervenção do Estado dificultam os avanços na implementação de políticas para o setor. O estudo mostra ainda que, apesar de o modelo histórico de concentração dos meios não ter sofrido

Radiodifusão alterações, o debate público sobre mudanças no marco legal avançou com as ações de atores da sociedade civil organizada, como o FNDC (Fórum Nacional pela Democratização da Comunicação. 


\begin{abstract}
Resumen:
El artículo analisa la proposición de un nuevo marco regulatorio para las comunicaciones en Brasil. Bajo el punto de vista de los aportes teóricos de la Economía Política de la Comunicación, describimos como la legislación existente y la ausencia de intervención del Estado dificultan el progreso para la implementación de política públicas en el sector. Nuestro estudio mostra que, aunque el modelo histórico de concentración de los medios no ha sido alterado, el debate público acerca de los cambios en el marco regulatorio ha avanzado por medio de las acciones de actores de la sociedad civil organizada como el FNDC (Foro Brasileño por la Democratización de la Comunicación).
\end{abstract}

\section{Palabras clave:}

Marco Regulatorio

Políticas de la Comunicación

Radiodifusión

\section{Keywords:}

Media regulation

Communication Policies

Media Broadcasting

\section{Abstract:}

This paper analyses the proposal of a new regulation for media and mass communication in Brazil. Based on concepts and theoretical analysis from the Political Economy of Communication, we characterize how the current legislation and the lack of intervention by the State present difficulties for the progress in implementing public policies in the segment. Our study shows that, albeit there is a traditional and historically unchanging model of concentration of media ownership, the public debate on making changes to the current regulation have advanced through the actions of organized civil society actor such as FNDC (Brazilian Forum for the Democratizing Communication). 


\section{Políticas de comunicação no Brasil: a proposta de um novo marco regulatório para a radiodifusão}

\section{Introdução}

A televisão aberta começou as operações no Brasil em 1950. Historicamente, o modelo de radiodifusão comercial é caracterizado pela predominância de poucos grupos televisivos no território nacional, sendo a TV Globo a líder de audiência.

Dentro da lógica capitalista de busca de audiência e de internacionalização econômica, os canais de rádio e TV investem em produtos homogêneos, restando pouco espaço para modelos alternativos, com produções culturais e regionais diversificadas.

Desde os primórdios, o modo de propriedade e controle da televisão no Brasil, a exemplo do contexto latino-americano, baseou-se no domínio de estruturas familiares detentoras dos poderes político e econômico.

Assim, ao longo de décadas do século $X X$, os sistemas de meios latino-americanos sustentaram práticas privadas na exploração de licenças de rádio e televisão que não precisaram da sanção de leis ou da produção de regulações estáveis. (BECERRA, 2011).

O caso brasileiro revela que a concentração da mídia remonta ao surgimento da televisão e se imbrica com a própria legislação responsável por regular o setor, cuja origem vem da década de 1960.

Outra característica da realidade brasileira é a ausência de políticas de comunicação direcionadas para a abertura de instâncias democráticas de participação social. Conforme Bolaño (2007), a Constituição Federal de 1988 trouxe o esboço de um modelo alternativo de comunicação, porém ainda não implementado efetivamente.

Nos últimos anos, não obstante, segmentos da sociedade civil organizada, liderados pelo Fórum Nacional pela Democratização da Comunicação (FNDC), se mobilizaram e propõem o estabelecimento de um novo marco regulatório para o setor, defendendo, entre outros pontos, a desconcentração econômica dos canais abertos e a proibição de concessões públicas para políticos.

O movimento ganhou força após a realização da $1^{\text {a }}$ Conferência Nacional de Comunicação (Confecom) em 2009 e reflete o entendimento de que a democratização da ação do Estado implica a participação da sociedade civil nas instâncias gestoras de políticas.

A atualização de marcos regulatórios, defendida na legislação internacional acerca do assunto e levada adiante em outros países latino-americanos, enfrenta a resistência dos empresários de radiodifusão no Brasil e não encontra reforço nas ações dos poderes Executivo e Legislativo, que não avançam na aprovação e execução de proposições na área.

Tomando como base os aportes teóricos da economia política da comunicação, o objetivo do artigo é discutir a proposta de um novo marco regulatório da comunicação no Brasil a partir da análise da legislação existente para o setor e das políticas necessárias para a área, conforme reivindicam os recentes movimentos pela democratização da mídia.

\section{A Unesco e o início do debate sobre políticas de comunicação}

As políticas de comunicação têm lugar, em nível mundial, nos debates da 
Unesco (Organização das Nações Unidas para a Educação, a Ciência e a Cultura) na década de 1970.

Naquele momento, as nações em desenvolvimento reivindicavam uma Nova Ordem Mundial da Informação e da Comunicação (NOMIC). Em sua forma mais radical, a NOMIC propunha a distribuição equitativa dos recursos de comunicação entre os países e mudanças profundas nos fundamentos legais e institucionais, que hoje regem as relações internacionais de comunicação.

Sob este ponto de vista, passou a ser questionado o livre fluxo de informações, visto que não correspondia ao equilíbrio esperado no acesso aos meios de comunicação.

Mesmo preocupada em não atingir a autonomia dos países membros, a Unesco recomendava que todo país deveria ter uma política nacional de comunicação, de características democráticas, participativas e a serviço do desenvolvimento nacional.

Assim, de acordo com Amorim (1988), quando se fala em políticas de comunicação pensa-se em discutir as políticas que assegurem a pluralidade das estruturas de produção e transmissão o acesso de todos às mensagens e a participação dos diversos grupos na sua definição.

Para a Unesco, o esforço para democratizar a comunicação não se esgota no plano das relações internacionais, havendo a necessidade também, em cada país, da adoção de sistemas nacionais democráticos de comunicação. Esse processo implicaria o desenvolvimento das dimensões do indivíduo enquanto ser político, cultural e social. Deste modo,

A Unesco entende por política nacional de comunicação um conjunto de regras e princípios tendo como objetivo estimular comportamentos desejáveis e inibir os inconvenientes. Insiste em que esta política deve ser global e explícita. Neste sentido, deve abranger todos os aspectos importantes da comunicação. Caberia, portanto, ao se formular uma política, tentar responder a perguntas tão variadas quanto saber se o sistema de comunicação deve ter caráter comercial ou saber se a comunicação deve ter um sentido eminentemente de entretenimento, ou também de educação e informação ou o que fazer para desenvolver a pesquisa em comunicação. (AMORIM, 1988, p. 21-22).

Diante da concentração dos meios de comunicação, fenômeno que se acentuou nas últimas décadas no contexto latino-americano, as políticas de comunicação também abarcam as ações do Estado que, conforme as concepções e legitimações de cada tempo histórico, orientam os destinos da criação, produção, difusão e consumo de produtos comunicativos e culturais, além de abranger iniciativas de segmentos da sociedade civil e do setor privado (BUSTAMANTE apud MORAES, 2009, p. 109).

As discussões do organismo multilateral culminaram com a publicação do Relatório MacBride (Um mundo e muitas vozes) em 1980, documento que identificou e sistematizou o problema da concentração dos meios e a relevância de mecanismos dos poderes públicos para salvaguardar a cultura nacional dos países e ampliar a participação social.

Como forma de fazer frente ao poderio da indústria midiática, os Estados têm praticado intervenções para regular os sistemas de radiodifusão, medidas adotadas principalmente na Argentina, Uruguai e Equador. O tema encontra lugar em investigações da economia política da comunicação, para a qual a indústria da comunicação se tornou parte integrante 
de uma grande ordem corporativa que é simultaneamente exploradora e anti-democrática. (MOSCO, 1999).

Essa preocupação com o interesse público perante os órgãos reguladores e políticos do Estado serve ao quadro brasileiro, no qual a temática da atualização do marco regulatório se ampliou na esfera da sociedade civil organizada, mas não avançou na agenda dos poderes Legislativo e Executivo.

\section{Comunicação, Estado e regulação}

Com a preponderância do mercado sobre os sistemas social, cultural e políti$\mathrm{co}$, um dos problemas enfrentados pelas nações tem sido a perda da autonomia do Estado em proteger os direitos dos cidadãos e regular os agentes e dinâmicas sociais e econômicas.

Jambeiro (2001) explica que, notadamente no final do século $X X$, esse cenário de domínio do livre mercado teve como consequência a substituição dos valores coletivos e públicos - tradicionalmente mediados pelo Estado - por valores individuais e empresariais.

Nesta perspectiva, o Estado deixou de regular diversas áreas da sociedade, cedendo lugar às forças do mercado. Com isso, surge a preocupação em resguardar os direitos dos cidadãos, uma vez que

Cabe aos Estados, nas sociedades contemporâneas, uma função de ordenação e de regulação das relações sociais e de composição de interesses individuais e sociais, frequentemente no âmbito da prossecução de políticas públicas. (GONÇALVES, 2003, p. 34).

Essa necessidade de proteção dos direitos dos cidadãos se verifica com o aprofundamento do processo de globalização, responsável por intensificar o re- cuo do Estado, inclusive nas políticas que tratam da comunicação. Assim:

Esta nova realidade revela a conseqüência mais visível da consolidação do processo de expansão do capitalismo na área das comunicações, hoje caracterizada pela conglomeração de empresas, globalização da produção, internacionalização e oligopolizaçäo do mercado, e cristalização da lógica capitalista nas relações entre os mídia e seus públicos. Isto pode não ser uma situação pretendida pela teoria liberal, no que se refere à economia de mercado e à democracia, mas sem dúvida é uma realidade concreta permitida por sua aplicação. Na medida em que se veja esta situação como não conducente ao exercício e ao aprofundamento da democracia, pode-se, portanto, concluir pela falha do mercado enquanto regulador da sociedade, e da democracia liberal enquanto sistema de gestão social, pelo menos no que se refere à área da comunicação de massa. (JAMBEIRO, 2001, p. 31).

Para Jambeiro (2001), as políticas nacionais dos países estariam se originando no interior das estruturas nacionais e internacionais de mercado. Neste sentido,

Ao invés do Estado e grupos de interesse da sociedade civil nacional, são as companhias multinacionais e as organizações internacionais, aliadas ou não a grupos nacionais, que estão ocupando a posição de principais forças nos processos regulatórios. No ambiente regulador da indústria da TV, por exemplo, ao invés dos governos e grupos nacionais de pressão lutando para conciliar interesses econômicos, políticos e culturais, estaríamos vendo agora grandes e poderosas corporações transnacionais ditando as regras 
para os serviços de televisão. (JAMBEIRO, 2001, p. 10).

A defesa da intervenção do Estado no setor das comunicações encontra base em uma ampla gama de autores da linha da economia política da comunicação'", para os quais a irrestrita liberdade de mercado no cenário de concentração midiática não garante o funcionamento adequado de mecanismos de participação e regulação.

Nesta perspectiva, a ação regulatória do Estado precisa zelar pelo equilíbrio entre o que deve ser público e o que pode ser privado, "inclusive deixando claro à população que as empresas de rádio e televisão não são proprietárias dos canais, apenas concessionárias de um serviço público com prazo de validade estabelecido em contrato" (MORAES, 2009, p. 195).

Ao analisar a lógica das políticas de comunicação e o embate entre os atores na construção da legislação para o setor no Brasil, Bolaño (2010) caracteriza o modelo de audiovisual como nacionalista e concentrador, em que prevaleceu a preocupação em proteger os capitais instalados da concorrência externa, a limitação da manifestação das expressões locais e do desenvolvimento de um panorama audiovisual diversificado, servindo basicamente aos interesses políticos e econômicos que se articulam no seu interior.

Nas últimas décadas, com a chegada ao poder de governos de orientação progressista em países latino-americanos, entendeu-se que a comunicação possui um caráter estratégico, não apenas para a formação de consensos sociais, mas também para a soberania nacional, o desenvolvimento cultural, a integração regional e a cooperação internacional (MORAES, 2009).

Sob este prisma, compreende-se a relevância da participação do poder público nos sistemas de informação e difusão cultural, por meio de ações direcionadas para a renovação de leis e marcos regulatórios das outorgas de rádio e televisão, no estímulo às produções regionais e independentes e no fortalecimento de canais públicos de comunicação.

Para Romão (2014), a democratização da ação do Estado também é um fenômeno que tem sido verificado com maior ênfase a partir do final da década de 1980, sendo a sociedade civil protagonista na abertura de espaços de debate e gestão de políticas.

Considerando que a radiodifusão é transmitida por meio de um recurso limitado - o espectro de frequências - a exploração privada desse bem público finito deve ter como fim os interesses da coletividade.

\section{Marco regulatório da comunicação no Brasil}

Ao longo da história, a radiodifusão comercial brasileira é caracterizada por uma série de falhas, como a ausência de transparência e de critérios nos processos de outorgas de canais de rádio e televisão; interferências políticas e irregularidades na obtenção e na renovação de licenças; inexistência de fiscalização e falta de mudanças estruturais no processo de participação social em relação às políticas do setor.

Instituído pela lei $n^{\circ} 4.117$, de 27 de agosto de 1962, o Código Brasileiro de Telecomunicações é o primeiro grande marco regulatório para os serviços de radiodifusão no país e segue em vigência até hoje. $\mathrm{O}$ dispositivo resistiu às mudanças tecnológicas e conserva intacto o texto que trata da radiodifusão, ao passo que as telecomunicações sofreram profundas transformações no decorrer da década de 1990, ganhando um novo marco legal com a Lei Geral de Telecomunicações. 
Com a Constituição Federal de 1988, a Comunicação Social ganhou um capítulo específico, com cinco artigos (do 220 ao 224) sobre o tema (BRASIL, 2010). O texto constitucional estabelece os princípios da radiodifusão, que deveriam se orientar para as finalidades educativas, artísticas, culturais e informativas; promover a cultura nacional e regional e estimular a produção independente.

A Constituição de 1988 também previu a proibição de monopólios e oligopólios nos meios de comunicação e a complementaridade dos sistemas privado, público e estatal.

Neste sentido, enquanto os setores de informática, telecomunicações e TV segmentada passaram por mudanças regulatórias, reforçando os mecanismos de mercado, a radiodifusão tradicional seguiu sem alterações e sob influência de poderosos interesses políticos e econômicos.

Acerca dos dispositivos legais que regem a comunicação,

Vivemos hoje um processo de mudança daquele modelo de regulação definido em 1962 e os contornos básicos do novo modelo já estão bastante claros. Quanto à questão regional, o problema da diversidade cultural, de estímulo à produção local e independente, enfim, toda a problemática da regulação dos conteúdos, numa perspectiva progressista, como aquela que figura nos princípios da Constituição de 1988, no capítulo sobre a matéria, ou não está tratada na legislação ou, quando está, os dispositivos não são cumpridos. (BOLAÑO, 2007, p. 95).

A análise do momento histórico da década de 1960 também considera que havia a centralidade do Poder Executivo no processo de outorgas e renovações das concessões de radiodifusão. A fun- ção centralizadora da União sofreu modificações com a Constituição Federal de 1988, que trouxe atribuições também ao Poder Legislativo.

Deste modo, segundo a Constituição, compete exclusivamente ao Congresso Nacional apreciar os atos de concessão e renovação de emissoras de rádio e televisão, além de a não-renovação das concessões depender da aprovação de, no mínimo, dois quintos do Congresso em votação nominal. (BRASIL, 2010).

O período que se segue é de inexistência de iniciativas de regulamentação dos dispositivos constitucionais. Com relação a esse quadro inalterado de regulação,

Outros dispositivos da Constituição tiveram destino ainda mais triste, não sendo implementados até hoje por falta de regulamentação posterior. É o conjunto desses dispositivos que pode ser entendido como a base para a construção de um novo modelo de regulação das comunicações que jamais chegou a concretizar-se no país. Cito os mais importantes: proibição do monopólio e do oligopólio nos meios de comunicação (artigo 220, parágrafo 5); preservação das finalidades educativas, culturais e informativas; proteção à cultura regional através da garantia de regionalização da produção; estímulo à produção independente (artigo 221); criação dos três modos complementares de exploração - privado, estatal e público (artigo 223). (BOLAÑO, 2007, p. 96).

Como consequência da imobilidade governamental em propor mudanças na legislação, entidades da sociedade civil organizada, representadas pelo Fórum Nacional pela Democratização da Comunicação, passaram a cobrar do poder público um novo marco legal para a radiodifusão. 
Esta iniciativa adquire maior expressão em 2009, quando ocorre a $1^{a}$ Conferência Nacional de Comunicação no país. O evento pode ser balizado como o momento em que a proposta de um novo marco regulatório efetivamente entra na agenda das discussões. Os principais atores envolvidos na conferência foram os radiodifusores, os poderes Executivo e Legislativo e a sociedade civil organizada.

Para Liedtke e Aguiar (2013), a Confecom representa uma conquista política oriunda das lutas pela cidadania e pela democratização dos meios de comunicação de massa no Brasil por parte das entidades populares. Conforme os autores,

A experiência em torno da $1^{\text {a }}$ Confecom demonstra o importante papel político da sociedade civil em prol da democratização da comunicação, unindo esforços para externar suas demandas em torno de um novo marco regulatório para a mídia brasileira debatidas no âmbito da conferência, cujas expectativas recaem, agora, sobre o Congresso Nacional, a quem cabe analisar os diversos projetos de lei em tramitação encaminhados pelo Executivo. (LIEDTKE; AGUIAR, 2013, p. 79).

A Confecom terminou com a aprovação de 633 resoluções que propuseram critérios democratizantes e mecanismos de transparência nas outorgas de rádio e TV. Entre as propostas, estão a regulamentação dos artigos da Constituição Federal, a proibição de concessões públicas de radiodifusão sonora e de sons e imagens a políticos, a realização de consultas públicas e audiências nos procedimentos de renovação das concessões e a constituição de um Conselho de Comunicação Social com poderes deliberativos.

O evento, realizado no final do Governo Lula, possibilitou a participação conjunta do Estado, sociedade civil e merca- do, sinalizando a possibilidade de avanços nas políticas de comunicação no Brasil. $O$ documento com o caderno de propostas sintetiza essa expectativa, ao mencionar os objetivos da conferência e suas consequências para os próximos anos:

A $1^{\text {a }}$ Confecom buscou fundamentar e atualizar os debates relacionados à Comunicação no país, de modo a fornecer subsídios para a elaboração e implementação de políticas públicas para o setor nos próximos anos, mesmo a Conferência não tendo caráter deliberativo. Por isso, é fundamental recuperar o processo de diálogos e negociações por meio do qual a Conferência se tornou possível, visando documentar esse debate democrático. (CONFECOM, 2010, p. 13).

$\mathrm{Na}$ análise do quadro das políticas de comunicação e regulação no contexto pós-Confecom, Bolaño (2010, p. 102) sintetiza que "é inegável no país o avanço na organização de uma esfera pública mais ampla que discute os problemas da comunicação, mas ainda falta traduzir esse avanço em conquistas concretas, materializadas na legislação".

Após a Confecom, o movimento social ocupado com a democratização da comunicação saiu fortalecido, buscando canais de diálogo com os poderes de Estado para viabilizar a execução das propostas debatidas e aprovadas.

Um dos primeiros movimentos neste sentido se deu com a realização do seminário "Marco regulatório - propostas para uma comunicação democrática" por iniciativa do Fórum Nacional pela Democratização da Comunicação. O evento, realizado no Rio de Janeiro em 2011, baseou-se nas sistematizações aprovadas e reunidas em documento final da Confecom e teve como meta reunir as sugestões da sociedade para a criação de uma 
plataforma com as contribuições para a consolidação de uma plataforma para um novo marco regulatório na área.

A primeira versão da proposta foi posta em consulta pública e obteve mais de 200 contribuições dos internautas, as quais foram analisadas e reunidas no documento final. O seminário serviu de base, portanto, para o lançamento da plataforma com os 20 pontos eleitos prioritários para democratizar as comunicações no país ${ }^{\mathrm{IV}}$, no intuito de o tema ser incluído na agenda política.

Uma das diretrizes para o novo marco regulatório das comunicações aborda a participação social que, segundo o documento, deve ser garantida em todas as instâncias e processos de formulação, implementação e avaliação de políticas de comunicação, sendo assegurada a representação ampla em instâncias de consulta dos órgãos reguladores ou com papeis afins e a realização de audiências e consultas públicas para a tomada de decisões.

No início de 2012, de acordo com o FNDC, o ministro das Comunicações Paulo Bernardo anunciou que colocaria em consulta pública o tema da regulação das comunicações, o que não ocorreu efetivamente.

A demora do governo em viabilizar a consulta pública acerca do assunto aumentou o descontentamento das organizações da sociedade civil. Desta forma, em agosto de 2012, na ocasião dos cinquenta anos de vigência do Código Brasileiro de Telecomunicações, o fórum lançou a campanha nacional "Para expressar a liberdade - uma nova lei para um novo tempo", cuja proposta era intensificar o diálogo da sociedade civil com a esfera governamental em defesa de uma nova regulação para a área.

A aglutinação dos atores sociais desencadeou o lançamento, em maio de 2013, do projeto de lei de iniciativa popular para uma Mídia Democrática. A proposta com- preende um instrumento político de pressão sobre os atores estatais que se propõe a levar ao Congresso Nacional uma lei que modifique a arquitetura institucional do sistema midiático brasileiro. (PROJETO..., 2013).

A proposta da sociedade civil para regulamentar a comunicação e garantir a organização de uma esfera de deliberação com participação social necessita de 1,5 milhão de assinaturas dos cidadãos para iniciar a tramitação no Poder Legislativo.

A redefinição de marcos regulatórios, como é proposta, é defendida pelos autores da economia política da comunicação, dado que representa a ação do Estado sobre o sistema de radiodifusão em defesa da democratização.

Estabelecer marcos regulatórios democráticos significa dotar os países de mecanismos legais para frear a concentração monopólica e a mercantilização, bem como atualizar normas para a concessão e a fiscalização das outorgas de rádio e televisão. A revisão da legislação pode favorecer também a produção nacional, regional, comunitária e educativa, com estabelecimento de cotas obrigatórias para exibição nas redes abertas e reserva de mercado para filmes nacionais nas salas de cinema, entre outros pontos. (MORAES, 2009, p. 141).

O tema também tem é reconhecido no direito internacional. Por consequência, "a construção de um sólido marco regulatório envolve tanto o estabelecimento, por lei, de políticas públicas com fortes objetivos e regras quanto a criação de uma autoridade reguladora independente que zelará pelo cumprimento da legislação" (MENDEL; SALOMON, 2011, p.12).

Entende-se, assim, que a participação do Estado na garantia de marcos legais que impeçam práticas monopóli- 
cas contribui para o aprofundamento da democracia. Segundo Moraes (2009), as disposições regulatórias devem envolver três instâncias principais: o Estado, a sociedade civil e o setor privado, cabendo ao primeiro - ator estatal - garantir o equilíbrio em termos de acesso, participação e representatividade aos setores envolvidos.

A análise do panorama brasileiro revela a dificuldade em estabelecer um debate público sobre as comunicações, tendo em vista a centralidade histórica da indústria da comunicação em poucos grupos familiares. Entrementes, alternativas democráticas surgem com a proeminência de atores da sociedade civil, que conseguiram a realização da Confecom e agora reivindicam as mudanças no modelo via novo marco regulatório.

\section{Considerações finais}

No presente momento, não há no Brasil uma política democrática para a comunicação. Essa constatação se reflete na imobilidade do governo de turno em dar continuidade às propostas aprovadas na $1^{\text {a }}$ Conferência Nacional de Comunicação, realizada em 2009.

O congestionamento de um debate público tanto na esfera do Executivo quanto Legislativo tem levado a sociedade civil organizada a conduzir esta discussão por meio de debates em universidades, associações sindicais, audiências públicas e pela internet.

A mobilização da sociedade civil, conduzida majoritariamente pelo Fórum Nacional pela Democratização da Comunicação, tem demonstrado a possibilidade de abertura de canais de discussão pública sobre temas de interesse coletivo.

A proposta de um novo marco regulatório para a comunicação deve ser compreendida como parte do processo de reconstrução democrática do espaço latino-americano, submetido há décadas ao neoliberalismo, cujos reflexos podem ser notados na concentração da mídia e no esvaziamento dos poderes do Estado.

\section{Bibliografia:}

ALBORNOZ, Luiz (comp.). Economia política da comunicação: uma perspectiva laboral. Revista Comunicação e Sociedade 1 - Cadernos do Nordeste, Braga, v.12, n.1-2, 1999.

AMORIM, José Salomão David. Políticas de comunicação no Brasil: evolução e impasse. In: GOMES, Pedro; PIVA, Marcia Cruz (orgs.). Políticas de Comunicação. São Paulo: Edições Paulinas, 1988. p-21-22.

BECERRA, Martín. A imaculada conceição dos meios latino-americanos em crise. In: BRITTOS, Valério (org.). Economia política da comunicação: convergência tecnológica e inclusão digital. Rio de Janeiro: Mauad X, 2011.p. 45-58.

BOLAÑO, César Ricardo Siqueira. O modelo brasileiro de regulação do audiovisual em perspectiva histórica. RECIIS - Revista Eletrônica de Comunicação, Informação \& Inovação em Saúde, Rio de Janeiro, v.4, n.4, nov. 2010. Disponível em: <http:// www.reciis.cict.fiocruz.br/index.php/reciis/article/ view/414/671>. Acesso em: 12 out. 2015.

BOLAÑO, César Ricardo Siqueira. Qual a lógica das políticas de comunicação no Brasil? São Paulo: Paulus, 2007. (Coleção Questões Fundamentais da Comunicação).

BRASIL. Constituição da República Federativa do Brasil. Senado Federal - Secretaria Especial de Editoração e Publicações. Brasília, 2010.

BUSTAMANTE, Enrique. Políticas de comunicación: un reto actual. IN: MORAGAS, Miquel de. (ed.). 
Sociología de la comunicación de masas: nuevos problemas y transformación tecnológica. Barcelona: Editorial Gustavo Gili, 1986. pp. 125-143.

CONFECOM. Caderno da $1^{a}$ Conferência Nacional de Comunicação. Secretaria de Comunicação Social da Presidência da República, 2010.

FNDC. Plataforma para um novo marco regulatório das comunicações no Brasil. 2011. Disponível em: <http://fndc.org.br/noticias/plataforma-para-um-novo-marco-regulatorio-das-comunicacoes-no-brasil-736321/>. Acesso em: 12 out. 2015.

GONÇALVES, Maria Eduarda. Direitos e regulação pública na sociedade da informação. In: Direito da informação: novos direitos e formas de regulação na sociedade da informação. Coimbra: Almedina, 2003.

JAMBEIRO, Othon. A regulação da TV no Brasil: 75 anos depois, o que temos? Estudos de Sociologia, Araraquara, v. 13, n. 24, pp. 85-104, 2008.

JAMBEIRO, Othon. A TV no Brasil no século $X X$. Bahia: EDUFBA, 2001.

LIEDTKE, Paulo; AGUIAR, Itamar. Políticas públicas de comunicação no Governo Lula (2003-2010): avanços e retrocessos rumo à democratização do setor. In: BRITTES, Juçara (org.). Saber militante: teoria e crítica nas políticas de comunicação do Brasil. Santa Maria: FACOS-UFSM; São Paulo: Intercom, 2013. pp. 65-84.

MENDEL, Toby; SALOMON, Eve. Liberdade de expressão e regulação da radiodifusão. Unesco, 2011. n. 8, fevereiro de 2011. Disponível em: <http://unesdoc.unesco.org/images/0019/001916/191623por. pdf>. Acesso em: 12 set. 2015. (Série Debates Comunicação e Informação).

MORAES, Dênis de. A batalha da mídia: governos progressistas e políticas de comunicação na América Latina e outros ensaios. Rio de Janeiro: Pão e Rosas, 2009.

MORAES, Dênis de. Sistema midiático, mercantilização cultural e poder mundial. In: MORAES, Dênis (org.). Mídia, poder e contrapoder: da concentração monopólica à democratização da informação. São Paulo: Boitempo, 2013. pp.19-52.

MOSCO, Vincent. La economia política de la comunicación: uma tradición viva. In: ALBORNOZ, Luiz (comp.). Poder, médios, cultura: uma mirada crítica desde la economia política de la comunicación. Buenos Aires: Paidós, 2011. pp. 61-90.
PROJETO DE LEI DE INICIATIVA POPULAR DA COMUNICAÇÃO SOCIAL ELETRÔNICA. 2013. Disponível em: <http://www.paraexpressaraliberdade.org.br/arquivosnocms/plip_versao_final. pdf>. Acesso em: 4 nov. 2015.

ROMÃO, Wagner de Melo. O eclipse da sociedade política nos estudos sobre o Orçamento Participativo. In: CARLOS, Euzenia; OLIVEIRA, Osmany Porto; ROMÃO, Wagner de Melo (orgs). Sociedade civil e políticas públicas: atores e instituições no Brasil contemporáneo. Chapecó: Argos, 2014. pp. 219-264.

\section{Recebido em 15/12/2015 \\ Aprovado em 06/02/2016}

I Carlos Henrique Demarchi. Doutorando e Mestre em Comunicação pela UNESP de Bauru. Docente do Centro Universitário Católico Salesiano Auxilium (UniSALESIANO). Contato: henriquejornalista@hotmail.com

II Maria Teresa Miceli Kerbauy. Doutora em Ciências Sociais pela PUC/SP. Docente do Programa de Pós-Graduação em Comunicação da UNESP/Campus de Bauru. Bolsista produtividade do CNPq. Contato: kerbauy@travelnet.com.br

III Originalmente, a economia política da comunicação tem se caracterizado por ser uma área de investigação com enfoque na concentração dos meios, na erosão da diversidade de conteúdos e do ponto de vista das classes sociais. De acordo com Mosco (2011), a área apresenta atualmente cinco tendências principais: a globalização da investigação na economia política da comunicação; a mudança de ênfase na investigação histórica; a busca de pontos de vista alternativos; a transição de ênfase dos meios tradicionais para os novos meios e a expansão do ativismo político (tradução nossa).

IV O texto consolidado após a consulta pública pode ser acessado no site <http://www.paraexpressaraliberdade.org.br/20-pontos-para-democratizar-a-comunicacao-no-brasil/> 